\title{
Commentary: Undress to redress internal thoracic artery could be the key!
}

\author{
Michele Di Mauro, $\mathrm{MD}, \mathrm{PhD},{ }^{\mathrm{a}}$ and Angela Di Baldassarre, $\mathrm{MD}, \mathrm{PhD}^{\mathrm{b}}$
}

\author{
From ${ }^{\mathrm{a} C}$ Cardiology and Cardiac Surgery, API Madonna Del Ponte, Lanciano; and ${ }^{\mathrm{b}}$ Department of Medicine and \\ Aging Sciences, University “G. D'Annunzio,” Chieti-Pescara, Italy. \\ Disclosures: Authors have nothing to disclose with regard to commercial support. \\ Received for publication Sept 22, 2018; accepted for publication Sept 24, 2018; available ahead of print Nov 9 , \\ 2018. \\ Address for reprints: Michele Di Mauro, MD, PhD, Heart Department, SS Annunziata Hospital, via dei Vestini, \\ 66100 Chieti, Italy (E-mail: mdimauro1973@gmail.com). \\ J Thorac Cardiovasc Surg 2019;157:1503-4 \\ $0022-5223 / \$ 36.00$ \\ Copyright (c) 2018 by The American Association for Thoracic Surgery \\ https://doi.org/10.1016/j.jtcvs.2018.09.083
}

When the left internal thoracic artery was definitively demonstrated to be the best graft for coronary artery bypass grafting, ' most surgeons proclaimed "Eureka! Eureka!" However, with the continuous increase in the number of patients with multivessel coronary disease requiring surgical grafting, and with the well-known poor long-term patency of the saphenous vein, it has become increasingly necessary to find other arterial conduits, such as the second thoracic or radial artery, mainly. Unfortunately, the double thoracic artery, although providing great advantages, meets nowadays considerable resistance in terms of use $3 \%$ in United States), ${ }^{2}$ due to either the increase in sternal complications or the difficulty in the arrangement that often leads the surgeons to opt for the veins. ${ }^{3}$ Even the radial artery meets some resistance as well, despite the data that tell us it is a conduit with enormous potential advantages. ${ }^{4}$ As already specified by Kajbafzadeh and colleagues, ${ }^{5}$ in roughly $30 \%$ of patients, for different reasons (polyvasculopathy, saphenectomy, decompensated diabetes, obesity, chronic obstructive pulmonary disease, renal failure in dialysis, etc), surgeons encounter great difficulty in finding enough conduits to be used for coronary artery bypass grafting. The strength of the study by Kajbafzadeh and colleagues ${ }^{5}$ is to offer a new solution for either the allo- or xenocoronary graft.

Tissue engineering has the purpose to replace or regenerate human tissues or organs to restore normal function. In our specific case, tissue engineering is used to provide small grafts from human cadavers (but not only!) without the risk of immune reactions. The tissue-engineering triad consists of 3 main factors, the cells, signaling molecules, and scaffold, which support and rely on one another.

To achieve this goal, we need to "undress" (decellularized) the internal thoracic artery so to rid the extracellular matrix (ECM) of native cells and genetic materials but keeping its structural, biochemical, and biomechanical cues. Once ECM is implanted, it can be "redressed"

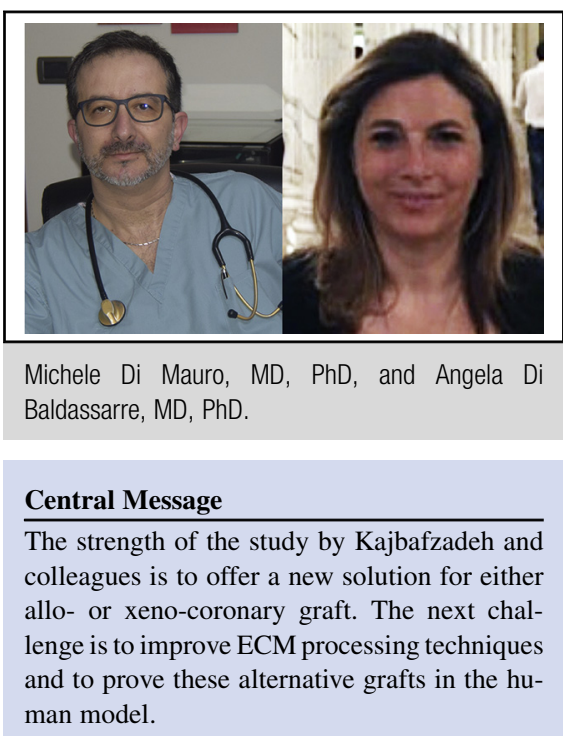

See Article page 1494.

(repopulated) with a patient's own cells to produce a personalized tissue, as clearly demonstrated by Kajbafzadeh and colleagues. ${ }^{5}$ ECM scaffolds are not inert but rather serve as an inductive niche to influence the cell behavior and the downstream tissue remodeling response: indeed, the presence of some bioactive molecules (types of collagens, glycosaminoglycans, growth factors, etc) exerts an immunomodulatory action that expedites the remodeling and the repair processes. Decellularized ECM has been successfully used to recreate various types of tissues and organs, including blood vessel, heart valve, cornea, trachea, esophagus, urinary bladder, kidney, liver, lung, and heart. ${ }^{6}$ To date, any limitation regarding the biocompatibility on seeding of human cells on foreign scaffold has been reported, which underlines the potential of efficiently decellularized xenogeneic organs in clinical use. Anyway, the use of xenogeneic sources is a point of debate because of the risk of disease transmission due to the failure in the optimization of decellularization or not fulfilling a certain standard of donor animals. Therefore, the next challenge is to improve ECM-processing techniques and to prove these alternative grafts in the human model.

\section{References}

1. Loop FD, Lytle BW, Cosgrove DM, Stewart RW, Goormastic M, Williams GW, et al. Influence of the internal-mammary-artery graft on 10-year survival and other cardiac events. N Engl J Med. 1986;314:1-6. 
2. LaPar DJ, Crosby IK, Rich JB, Quader MA, Speir AM, Kern JA, et al; Investigators for the Virginia Cardiac Surgery Quality Initiative. Bilateral internal mammary artery use for coronary artery bypass grafting remains underutilized: a propensity-matched multi-institution analysis. Ann Thorac Surg. 2015;100: 8-14.

3. Calafiore AM, Iacò AL, Di Mauro M. Spending 30 minutes to add years to a patient's life: why is the last step so difficult? J Thorac Cardiovasc Surg. 2015;150: $321-2$.
4. Gaudino M, Benedetto U, Fremes S, Biondi-Zoccai G, Sedrakyan A, Puskas JD, et al; RADIAL Investigators. Radial-artery or saphenous-vein grafts in coronary-artery bypass surgery. N Engl J Med. 2018;378:2069-77.

5. Kajbafzadeh AM, Khorramirouz R, Kameli SM, Fendereskia K, Daryabaria SS, Tavangar SM, et al. Three-year efficacy and patency followup of decellularized human internal mammary artery as a novel vascular graft in animal models. J Thorac Cardiovasc Surg. 2019;157:1494-502.

6. Gilpin A, Yang Y. Decellularization strategies for regenerative medicine: from processing techniques to applications. Biomed Res Int. 2017;2017:9831534. 